\title{
Fatores preditivos para drenagem de derrames pleurais parapneumônicos em crianças"
}

\author{
Helena Teresinha Mocelin ${ }^{1}$, Gilberto Bueno FisCHeR ${ }^{2}$
}

Objetivo: Avaliar os critérios de Light et al. para drenagem em derrames pleurais parapneumônicos (DPP) em crianças. Métodos: Estudo transversal prospectivo realizado com 85 crianças admitidas no Hospital da Criança Santo Antônio, Porto Alegre, no Estado do Rio Grande do Sul, região Sul do Brasil, que apresentaram pneumonia e derrame pleural confirmado por radiografia de tórax e/ou ultra-sonografia. Os critérios de exclusão foram: drenagem prévia, derrame associado com outras doenças. A análise do $\mathrm{pH}$ foi em aparelho de gasometria. Glicose e desidrogenase láctica foram analisadas por espectrofotometria. A indicação de drenagem foi feita pelo médico assistente sem participação dos pesquisadores. Resultados: Neste estudo, os DPP com pH menor que 7,2 e glicose igual ou inferior a $40 \mathrm{mg} / \mathrm{dl}$ apresentaram indices de drenagem superiores aos da DHL $>1.000 \mathrm{UI} / \mathrm{l}$. O

$\mathrm{pH}$ e a glicose apresentaram especificidades elevadas na predição de drenagem (89\% e 88\%) e superiores às da DHL (65\%). Os mesmos resultados foram observados quando líquidos não purulentos foram analisados ( $\mathrm{pH}<7,2-94 \%$; glicose $<40-88 \%$; e $\mathrm{DHL}>1.000-68 \%$ ). Em pacientes com $\mathrm{pH}<7$, DHL $>1.000 \mathrm{UI} / \mathrm{l}$ e glicose $\leq 40 \mathrm{mg} / \mathrm{dl}$ predominaram líquidos com aspecto turvo ou purulento. Em torno de $21 \%$ dos pacientes com indicação de drenagem, segundo os critérios bioquímicos, encontrou-se líquido com aspecto límpido. Conclusões: Estes dados indicam que os exames bioquímicos podem apoiar a decisão de drenagem torácica de derrame pleural parapneumônico em líquidos não purulentos. A especificidade para drenagem foi de $89 \%$ para o $\mathrm{pH}$, 88\% para glicose e em torno de 65\% para DHL. (J Pneumol 2001;27(4):177-184)

\section{Predictive factors for pleural drainage in children with parapneumonic pleural effusion}

Objective: To evaluate Light's criteria for drainage in children with parapneumonic pleural effusion. Methods: Prospective cross-sectional study on 85 children who were admitted to Hospital da Criança Santo Antônio, State of Rio Grande do Sul, Southern Brazil, presenting pneumonia with pleural effusion confirmed by chest X-ray and/or chest ultrasonography. The exclusion criteria were: previous drainage, pleural effusions associated with other disorders. The pH analysis was performed with a blood gas analyzer. Glucose and LDH were analyzed by spectrophotometry. The decision to perform pleural drainage was made by the attending physician without the participation of the researchers. Results: Pleural fluid in parapneumonic effusion with $\mathrm{pH}<7.2$ and glucose $<40 \mathrm{mg} / \mathrm{dl}$ presented higher drainage rate than $\mathrm{LDH}>1,000$ UI/l. The pH and glucose had high specificity (89\% and 88\%) and above the LDH (65\%). The same results were observed when non-purulent fluids were analyzed $(\mathrm{pH}<7.294 \%$, glucose $88 \%$, LDH

68\%). In patients with $\mathrm{pH}<7.2 \mathrm{LDH}>1,000 \mathrm{UI} / \mathrm{l}$ and glucose $\leq 40 \mathrm{mg} / \mathrm{dl}$ predominated fluid with cloudy or purulent aspect. In more than $21 \%$ of patients who have indication of drainage by

* Trabalho realizado no Serviço de Pneumologia do Hospital da Criança Santo Antônio, Porto Alegre, RS. O trabalho original é Dissertação de Mestrado "Fatores preditivos para drenagem de derrame pleural parapneumônico em crianças", apresentada em 12 de março de 1998 na Universidade Federal do Rio Grande do Sul, Porto Alegre, RS, com aprovação. Autora: Helena Mocelin; Orientador: Dr. Gilberto Bueno Fischer.
1. Mestre em Pediatria-UFRGS; Médica Pneumologista Pediátrica do Hospital da Criança Santo Antônio.

2. Professor Titular da FFFCMPA; Doutor em Pneumologia-UFRGS.

Endereço para correspondência - Helena Mocelin, Av. Ceará, 1.549 - 90240-512 - Porto Alegre, RS. Tel. (51) 330-6558; E-mail: hmocelin @zaz.com.br

Recebido para publicação em 8/11/00. Aprovado, após revisão, em 13/3/01. 
the classic criteria, was found limpid aspect. Conclusions: These data indicate that biochemical test support indication of drainage in children presenting with parapneumonic pleural effusion in non-purulent fluid. The specificity for drainage was $89 \%$ for $\mathrm{pH}$ and $88 \%$ for glucose and around $65 \%$ for $L D H$.

Descritores - Derrame pleural. Empiema pleural. Drenagem postural.

Key words - Pleural effusion. Pleural empyema. Postural drainage.

\section{INTRODUÇÃO}

O derrame pleural (DP) é a principal complicação de pneumonias em crianças. Ochsner cita que o prognóstico baseado nas características de líquido pleural e a necessidade de drenagem de empiemas já foram descritos no século V a.C. por Hipócrates, que sugeriu: "Em casos de empiema tratados com cautério ou incisão, quando o material é puro, claro e não é fétido, o paciente se recupera; se é sanguinolento e com características de sujo, ele morre"(1). A idéia de que o derrame pleural purulento deve ser drenado sempre foi aceita devido a sua alta morbidade, apesar das limitações nas técnicas utilizadas para drenagem $^{(1-3)}$. A principal dúvida que ocorre com a presença de líquido no espaço pleural em pneumonias é: quando o líquido não purulento irá evoluir para a necessidade de drenagem ${ }^{(4-8)}$ ?

No início de década de 70, Light et al. tentaram estabelecer critérios para a indicação desse procedimento em pacientes adultos. Utilizaram vários critérios, desde o aspecto macroscópico a alterações bioquímicas do líquido pleural para estabelecer a potencial evolução para a necessidade de drenagem assim como para a diferenciação entre exsudatos e transudatos. Assim, quando o derrame é complicado ( $\mathrm{pH}<7$ e/ou glicose $<40 \mathrm{mg} / \mathrm{dl}$ e/ou gram ou cultura positivos), o paciente necessita de drenagem para que sua evolução seja favorável(4,9-11). Apesar da alta prevalência de derrame pleural parapneumônico em $\mathrm{Pe}$ diatria, poucos estudos têm sido realizados com metodologia adequada e não encontramos na literatura pesquisas que avaliassem a aplicação de critérios bioquímicos na indicação de drenagem torácica em crianças $^{(12)}$. O presente estudo procurou avaliar a associação dos critérios bioquímicos utilizados por Light et al. ${ }^{(4,9-11)} \mathrm{com}$ a realização de drenagem em derrames pleurais parapneumônicos em crianças.

\section{PACIENTES E MÉTODOS}

O trabalho foi realizado no Hospital da Criança Santo Antônio, de Porto Alegre (HCSA), no período de $1^{\circ}$ de novembro de 1995 a 31 de outubro de 1996.
Siglas e abreviaturas utilizadas neste trabalho

DHL - Desidrogenase láctica

DP - Derrame pleural

DPP - Derrame pleural parapneumônico

Cálculo do tamanho da amostra: Os dados utilizados para o cálculo do tamanho da amostra basearam-se num estudo prévio realizado por um dos autores na mesma instituição (trabalho não publicado, apresentado como tema livre no Congresso de Pneumologia Pediátrica, 1991). Aquela pesquisa permitiu identificar a provável proporção de pacientes admitidos com derrame pleural e a freqüência de drenagem. Estabeleceram-se $\alpha=5 \%$ e $\beta=$ $20 \%$ considerando-se ocorrência de drenagem entre pacientes com $\mathrm{pH}$ menor que 7 de $90 \%$ e, de $60 \%$ para $\mathrm{pH}$ maior que 7,2; estimou-se um tamanho de amostra de 76 pacientes.

Aspectos éticos: $O$ estudo foi realizado após aprovação da comissão de ética do HCSA e, como a pesquisa não implicava nenhuma coleta adicional de material ou exames para o paciente, o estudo foi realizado após consentimento verbal dado pelo responsável pela criança.

Foi realizado um estudo transversal com crianças admitidas no HCSA com derrame associado à pneumonia que eram submetidas à toracocentese com análise do $\mathrm{pH}$, glicose e DHL no líquido pleural e observava-se de maneira independente se eram drenados posteriormente.

Foram incluídas crianças entre um mês de idade até 14 anos, com quadro clínico de pneumonia e derrame pleural visualizado na radiografia de tórax e/ou ultra-sonografia e confirmado com a retirada de líquido por toracocentese. Foram excluídas aquelas com drenagem pleural prévia, derrames de outras etiologias (não exsudativos) e portadores de outras doenças associadas (imunodeficiências, bronquiolite obliterante, tuberculose, mucoviscidose). A equipe de pesquisa era informada através de comunicação eletrônica imediatamente após a admissão de crianças com essa complicação. A toracocentese foi realizada, num período de até duas horas após a indicação do procedimento, pela equipe de pesquisa, que foi especialmente treinada no período prévio à realização do estudo. Após a coleta de material para os exames de rotina, foram colhidas duas amostras para o estudo. Uma amostra em anaerobiose para leitura imediata do $\mathrm{pH}$ em aparelho de 
gasometria e outra congelada para análise da glicose e DHL por espectrofotometria, realizada posteriormente pela pesquisadora HTM. A identificação do agente etiológico foi feita seguindo os procedimentos de rotina do laboratório do HCSA (exame bacterioscópico com coloração de Gram e cultural em meios para identificar os principais agentes bacterianos gram-positivos e negativos). O tempo de hospitalização foi definido como o tempo de permanência no hospital devido à pneumonia com DPP e o tempo de duração da febre foi caracterizado como o número de dias até a criança permanecer 48 horas com temperatura axilar inferior a $37,5^{\circ} \mathrm{C}$.

As radiografias de tórax foram analisadas por um radiologista pediátrico. O volume do DPP foi classificado como pequeno (comprometendo menos de $1 / 3$ do hemitórax); moderado (ocupando até $2 / 3$ ) e volumoso (opacidade de mais de 2/3).

Análise estatística: Os dados foram codificados $e$, após, armazenados e analisados no programa Epi-Info versão 6.0. Realizou-se, inicialmente, uma análise descritiva da amostra. Fez-se, a seguir, uma análise bivariada dos fatores em estudo - $\mathrm{pH}$, glicose e DHL - com o desfecho, realização ou não de drenagem pleural. Foram verificadas, também, a sensibilidade e a especificidade daquelas variáveis em relação ao desfecho. Um valor de $\mathrm{p}<$ 0,05 foi considerado estatisticamente significante.

\section{RESULTADOS}

Foram estudadas 85 crianças com idade entre três meses e 12 anos, com discreto predomínio do sexo masculino $(55 \%)$. A toracocentese foi realizada nas primeiras 24 horas após o diagnóstico de DP em $84 \%$ dos casos. O volume do DP avaliado por radiografia de tórax em 69 crianças foi classificado como pequeno em $35 \%$, moderado em $35 \%$ e volumoso em $30 \%$, de acordo com a descrição do radiologista que analisou de maneira independente os exames.

Os resultados da análise bioquímica podem ser observados no Gráfico 1. A aferição do $\mathrm{pH}$ foi realizada em 74 crianças e a média foi de 7,06, variando de 6,06 a 7,70, com desvio padrão de 0,32 . Nos demais pacientes, o pH não foi realizado porque a amostra não pôde ser coletada em condições adequadas, por defeito no aparelho de gasometria para análise ou por ocorrência de líquido muito espesso que impossibilita sua leitura no aparelho.

A concentração de glicose no líquido pleural variou de zero a $255 \mathrm{mg} / \mathrm{dl}$, sendo em média de $41 \mathrm{mg} / \mathrm{dl}$, mediana de 25 (desvio padrão $=46$ ), com discreto predomínio de valores inferiores a $40 \mathrm{mg} / \mathrm{dl}$. Sete pacientes apresentavam niveis de glicose maiores do que $100 \mathrm{mg} / \mathrm{dl}$ e, destes, apenas um estava recebendo infusão de solução glicosada durante a punção.

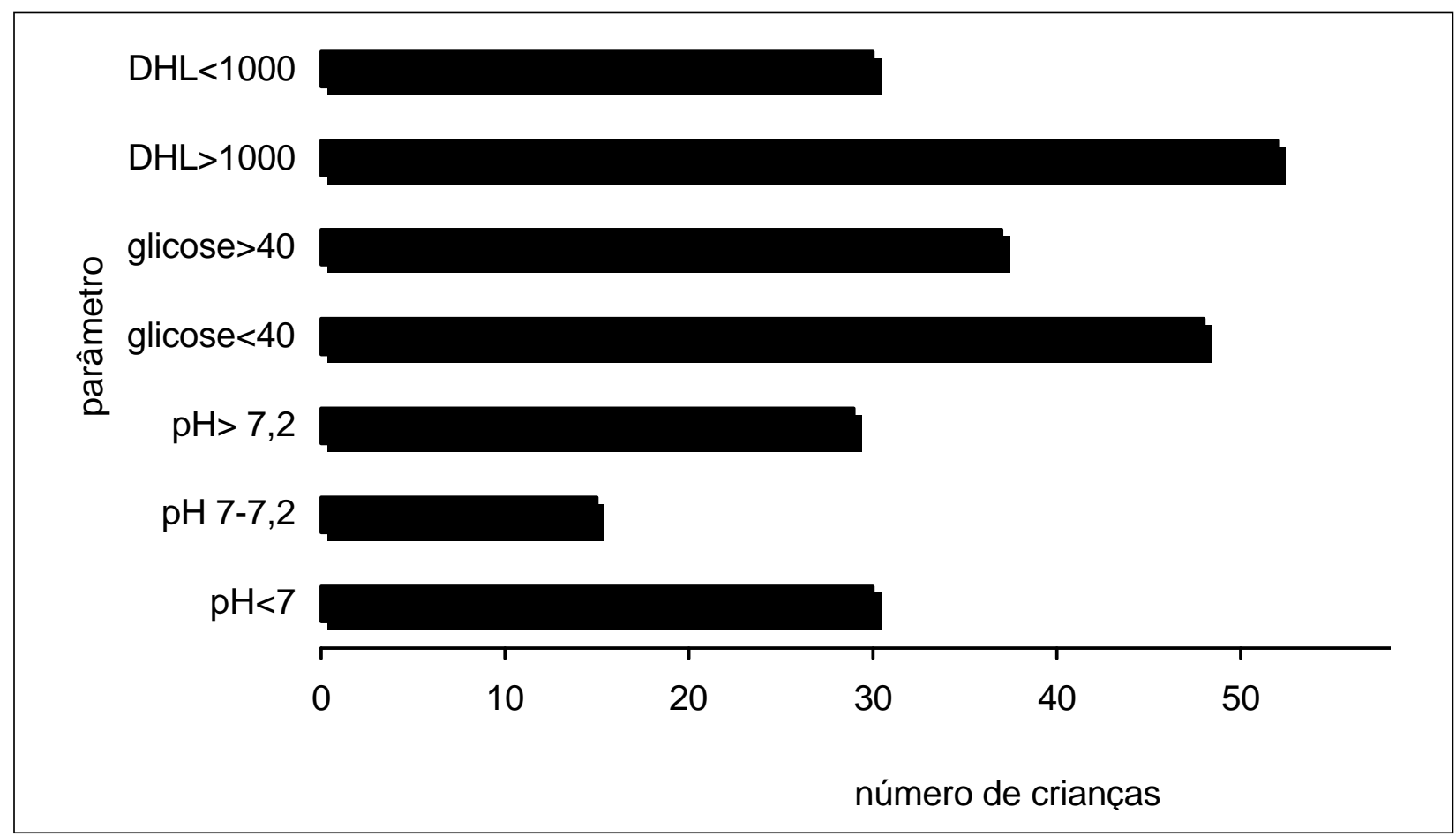

Gráfico 1 - Características bioquímicas do líquido pleural

Obs.: devido a material insuficiente ou líquido muito espesso, a análise do pH não foi realizada em 11 e a DHL em duas crianças. 
Encontraram-se niveis de DHL entre 200 e $31.650 U \mathrm{U} /$ 1, em média de 4.590UI/l, mediana de 1.865 (desvio padrão $=6.844)$; a maioria dos pacientes $(63 \%)$ apresentava níveis maiores do que $1.000 \mathrm{UI} / 1$.

$\mathrm{Na}$ Tabela 1, observa-se que, nos pacientes que apresentavam $\mathrm{pH}$ menor que 7 , DHL maior que 1.000UI/l e glicose $\leq 40 \mathrm{mg} / \mathrm{dl}$, predominavam líquidos com aspecto turvo ou purulento. Em mais de $20 \%$ dos pacientes, para os quais havia indicação de drenagem, segundo os critérios bioquímicos clássicos, encontrou-se líquido com aspecto limpido. Em um paciente não se registrou o aspecto.

TABELA 1

Associação dos critérios de Light et al. e o aspecto macroscópico

\begin{tabular}{lrrr} 
Característica bioquímica & \multicolumn{3}{c}{ Aspecto do líquido } \\
\cline { 2 - 4 } & Límpido & Turvo & Purulento \\
\hline $\mathrm{pH}<7(\mathrm{n}=30)$ & $7(23 \%)$ & $12(40 \%)$ & $11(37 \%)$ \\
$\mathrm{Glicose} \leq 40(\mathrm{n}=48)$ & $13(27 \%)$ & $18(38 \%)$ & $17(35 \%)$ \\
$\mathrm{DHL}>1.000(\mathrm{n}=52)$ & $11(21 \%)$ & $23(44 \%)$ & $18(35 \%)$ \\
\hline
\end{tabular}

Dos 85 pacientes estudados, 59 foram drenados. Para fins de análise os pacientes foram classificados em dois grupos quanto ao desfecho da drenagem. Nos dois grupos os pacientes eram semelhantes entre si quanto à idade, ao gênero, ao tempo de evolução dos sintomas antes da toracocentese e ao uso prévio de antibióticos. Houve diferença estatisticamente significante na indicação de drenagem quando o aspecto do líquido era purulento comparado com líquidos não purulentos. Tal diferença não se observou entre líquidos límpidos e turvos.

Chama a atenção que $74 \%$ dos pacientes já faziam uso de antibióticos antes da realização da toracocentese e cerca de $50 \%$ dos pacientes receberam oxigenoterapia e infusão endovenosa de solução glicosada durante a punção. Não se observou diferença estatística nas concentrações de glicose entre os pacientes que recebiam infusão de solução glicosada e os que não a recebiam $(p=0,9)$.

A associação entre os parâmetros bioquímicos e a realização de drenagem pode ser observada na Tabela 2. Os valores de $\mathrm{pH}$ menores que 7,2 e glicose igual ou inferior a $40 \mathrm{mg} / \mathrm{dl}$ apresentaram índices de drenagem superiores aos da DHL maior que 1.000UI/1. Verifica-se que tanto o $\mathrm{pH}$ quanto a glicose apresentam especificidades elevadas

TABELA 2

Associação dos parâmetros bioquímicos com drenagem pleural

\begin{tabular}{lccrrr}
\hline Parâmetro & Sensibilidade & Especificidade & VPP & VPN & \multicolumn{1}{c}{ RRe IC } \\
\hline \multirow{2}{*}{$\mathrm{pH}<7,0$} & $55 \%$ & $95 \%$ & $97 \%$ & $45 \%$ & $1,77(1,34-2,34)$ \\
& $* 47 \%$ & $* 95 \%$ & $* 94 \%$ & $* 48 \%$ & $* 1,85(1,34-2,55)$ \\
$\mathrm{pH}<7,2$ & $79 \%$ & $86 \%$ & $93 \%$ & $62 \%$ & $2,46(1,53-3,95)$ \\
& $* 67 \%$ & $* 94 \%$ & $* 96 \%$ & $* 60 \%$ & $* 2,40(1,54-3,75)$ \\
Glicose $\leq 40 \mathrm{mg}$ & $76 \%$ & $88 \%$ & $94 \%$ & $62 \%$ & $2,48(1,63-3,77)$ \\
& $* 72 \%$ & $* 88 \%$ & $* 90 \%$ & $* 66 \%$ & $* 2,71(1,65-4,45)$ \\
$\mathrm{DHL}>1.000 \mathrm{UI} / \mathrm{l}$ & $77 \%$ & $65 \%$ & $83 \%$ & $57 \%$ & $1,91(1,24-2,93)$ \\
& $* 73 \%$ & $* 68 \%$ & $* 77 \%$ & $* 63 \%$ & $2,08(1,23-3,52)$ \\
\hline
\end{tabular}

$\mathrm{VPP}=$ valor preditivo positivo; $\mathrm{VPN}=$ valor preditivo negativo; $\mathrm{RR}=$ risco relativo; $\mathrm{IC}=$ intervalo de confiança; os valores marcados com ${ }^{*}$ ) representam a sensibilidade e a especificidade quando se excluíram os líquidos purulentos.

TABELA 3

Distribuição dos achados etiológicos

\begin{tabular}{lcccr}
\hline \multirow{2}{*}{ Bactéria identificada } & \multicolumn{4}{c}{ Identificação } \\
\cline { 2 - 5 } & Hemocultura & Cultura LP & Bacterioscópico LP & Total \\
\hline S. pneumoniae & 5 & 13 & 9 & 14 \\
S. aureus & 2 & 1 & - & 3 \\
H. influenzae & 1 & 1 & - & 1 \\
S. aureus coagulase negativo & 2 & 1 & - & 3 \\
Streptococcus $\alpha$-hemolítico & - & 2 & 1 & 2 \\
Flora mista & - & 1 & - & 2 \\
Enterobacter & - & & & 1 \\
\hline
\end{tabular}


e superiores à DHL quanto à indicação de drenagem. O mesmo se verificou quando se analisaram somente os líquidos não purulentos.

Quando se analisou o volume do DPP, observou-se que, dos 24 pacientes com derrames de pequeno volume, $59 \%$ apresentavam glicose $<40 \mathrm{mg} / \mathrm{dl}$ e $61 \% \mathrm{pH}<7,2$. Dezessete destes pacientes foram drenados.

Realizou-se a cultura do líquido pleural em 83 crianças e a hemocultura em 69; em duas crianças não foi realizado nenhum dos exames. Destaca-se que foi possivel identificar alguma bactéria em 26 das 83 crianças (31\%); os resultados são apresentados na Tabela 3. Identificou-se o agente etiológico, através da cultura do líquido pleural em 21 pacientes (25\%); através da hemocultura, em dez (15\%). Em cinco pacientes um microrganismo foi isolado, simultaneamente, nas amostras do líquido pleural e no sangue. Nesse processo, foi possivel constatar que a cultura do líquido pleural apresentou maior sensibilidade que a hemocultura na identificação do agente etiológico.

Dezenove (90\%) pacientes que apresentavam crescimento de bactérias no líquido pleural foram submetidos à drenagem; nos dois que evoluíram sem drenagem, em um deles observou-se flora mista e, em outro, Enterobacter sp.

O tempo de hospitalização variou de quatro a 37 dias, com média de 15 dias, sendo que $95 \%$ das crianças permaneceram hospitalizadas por mais de sete dias. O grupo de pacientes submetidos a drenagem permaneceu internado em média 17 dias (desvio padrão $=6,42$ ) e, o que não foi drenado, dez dias (desvio padrão $=2,81$ ). Observouse também que todos os pacientes com tempo de internação maior que 16 dias pertenciam ao grupo drenado.

Como forma de estudar outros desfechos além da drenagem pleural, estudou-se a associação entre os parâmetros bioquímicos e a evolução dos pacientes durante a internação, destacando-se que as crianças com pH menor que 7 , glicose igual ou inferior a $40 \mathrm{mg} / \mathrm{dl}$ e DHL maior do que $1.000 \mathrm{UI} / \mathrm{l}$ apresentaram maior tempo de febre $e$ de hospitalização que o grupo sem esses parâmetros, como pode ser observado na Tabela 4 . Com ambos os desfechos verificou-se significância estatística nas associações.

Para a avaliação do tempo de febre e do tempo de hospitalização, utilizou-se o ponto de corte de oito dias, a média de duração da febre. Nos pacientes com febre durante mais que oito dias, a média do $\mathrm{pH}$ foi de 6,91; da glicose, $24 \mathrm{mg} / \mathrm{dl}$; e da DHL, $6.749 \mathrm{UI} / 1$. Nas crianças com febre por período menor que oito dias, a média do $\mathrm{pH}$ foi de 7,19; da glicose, 55mg/dl; e da DHL, 2.724UI/l. Houve, também, diferença na média desses três parâmetros, quando comparados com o tempo de internação: para pacientes com hospitalização maior do que oito dias, a média do $\mathrm{pH}$ foi de 7,02; da glicose, 34mg/dl; e da DHL, $5.104 \mathrm{UI} / \mathrm{l}$, enquanto naqueles com internação menor que oito dias a média do $\mathrm{pH}$ foi de 7,32; da glicose, $93 \mathrm{mg} / \mathrm{dl}$; e da DHL, 884UI/1.

\section{DISCUSSÃO}

Apesar da freqüência com que ocorre o derrame pleural parapneumônico em Pediatria, as decisões quanto à terapêutica ainda são controversas, especialmente quanto à realização da drenagem pleural. A maioria dos estudos relativos a orientações para o tratamento do derrame, além de ter sido realizados com adultos, apresentam falhas metodológicas, as quais conduzem a resultados questionáveis ${ }^{(12)}$. Os critérios para indicação de drenagem citados na literatura são aspecto macroscópico do líquido, volume, tipo de germe identificado e características bioquímicas que sugiram a presença de empiema ${ }^{(11-16)}$. No presente estudo, pretendeu-se avaliar especialmente a associação das características bioquímicas do líquido pleural (pH, glicose e DHL) com a indicação de drenagem, em pacientes da faixa etária pediátrica, utilizando metodologia adequada para esse fim. A principal limitação deste estudo, assim como a descrita por outros autores que estudaram o mesmo tema, foi encontrar um desfecho que pudesse ser bem caracterizado, sem a intervenção dos pesquisadores. No entanto, puderam-se ter como critério de adequação da escolha desse desfecho comparações com outros parâmetros, como tempo de internação e tempo de febre, que neste estudo foram significativamente maiores nos pacientes com parâmetros bioquímicos clássicos indicativos de drenagem.

Eventuais diferenças nos critérios de drenagem poderiam influenciar os resultados, porém sem prejuizo para

TABELA 4

Associação entre as características bioquímicas do líquido pleural com o tempo de febre e tempo de internação

\begin{tabular}{|c|c|c|c|c|c|c|}
\hline \multirow[t]{2}{*}{ Parâmetro } & \multicolumn{2}{|c|}{ Tempo de febre após internação } & \multirow[t]{2}{*}{$\mathbf{p}$} & \multicolumn{2}{|c|}{ Tempo de internação } & \multirow[t]{2}{*}{$\mathbf{p}$} \\
\hline & $\leq 8$ dias & $>8$ dias & & $\leq 8$ dias & $>8$ dias & \\
\hline $\mathrm{pH}<7$ & 8 & 21 & 0,002 & 0 & 30 & 0,008 \\
\hline $\mathrm{DHL}>1.000$ & 21 & 31 & 0,003 & 2 & 50 & 0,004 \\
\hline Glicose $\leq 40$ & 16 & 31 & 0,0002 & 16 & 31 & 0,0002 \\
\hline
\end{tabular}


as diferenças encontradas entre os parâmetros bioquímicos, pois essas análises não eram de conhecimento daqueles que indicavam a drenagem, assim como não houve intervenção dos pesquisadores naquela decisão. A influência dos pesquisadores foi evitada mantendo-se a rotina de atendimento dos pacientes com derrame pleural; o médico assistente determinava quais os exames a serem coletados e quais os critérios que norteariam sua conduta. Além disso, apenas a leitura do $\mathrm{pH}$ foi realizada no local do estudo, devido à necessidade de ser feita imediatamente após a coleta e os resultados não eram disponibilizados para o médico assistente. As dosagens de DHL e glicose utilizadas para as associações foram realizadas em tempo diferente dos exames coletados na rotina e em outro laboratório especificamente para esta pesquisa. Com esses cuidados, os exames que poderiam influenciar na decisão de drenagem eram avaliados pelos médicos assistentes sem a participação da pesquisadora principal.

O expressivo número de crianças estudadas proporcionou uma amostra bem maior que a utilizada na maioria dos estudos descritos na literatura. Além disso, aqui foram incluídas apenas crianças com derrame pleural parapneumônico, o que torna a amostra mais homogênea $e$ exclui situações que predispõem ao aumento na incidência e à pior evolução do derrame. Embora, entre crianças, os derrames pleurais parapneumônicos representem a maioria das efusões pleurais, foi útil dosar a DHL, pois esse procedimento permitiu em nosso estudo identificar eventuais inclusões de transudatos. Todos os pacientes estudados tinham DHL superior a 200UI/l, conforme preconizado por Light et al. para caracterização de exsudato ${ }^{(9)}$. Em três pacientes o nivel de glicose foi indetectável. Seguindo os parâmetros de Light et al., não há diferença entre valores indetectáveis e inferiores a $40 \mathrm{mg} / \mathrm{dl}$.

Um ponto que poderia ser questionado é o alto número de pacientes drenados. Uma possivel explicação é o fato de incluir apenas pacientes com critérios bem definidos, ou seja, derrames com volume suficiente para análise, ausência de doença prévia, evolução aguda. Alguns estudos que apresentam menor freqüência de drenagem incluem DP de pequeno volume e não puncionados, DP de outras etiologias $e$, alguns, pacientes com evolução mais prolongada ${ }^{(16)}$. Todas essas condições poderiam aumentar o número de pacientes que não teriam indicação de drenagem. Neste estudo, o volume do derrame observado na radiografia prévio à toracocentese não foi preditivo de drenagem, pois, na maioria dos casos, mesmo em derrames de pequeno volume, já havia alterações bioquímicas indicativas de drenagem.

No presente estudo, foi possivel obter a análise dos três parâmetros avaliados, num mesmo momento, em 74 crianças, o que resultou em um número bem maior que o dos relatados na literatura. Concordando com o sugerido por Heffner et al.(12) - que para determinar a acurácia relativa desses testes, é necessário aplicar o conjunto dos testes à totalidade dos pacientes - foi possivel aplicar os três testes a 74 crianças, número semelhante ao estimado pelo cálculo do tamanho da amostra.

Light et al. sugeriram que os aspectos diagnósticos mais importantes para a indicação de drenagem, no derrame pleural parapneumônico, são, em ordem decrescente: o aspecto do líquido (incluindo o odor), o $\mathrm{pH}$, a glicose e a $\mathrm{DHL}^{(10)}$. Os achados do presente estudo confirmam essa hierarquia em relação aos parâmetros bioquímicos e destacam o pH como um excelente indicador da necessidade de drenagem torácica no derrame pleural parapneumônico, o que está de acordo com outros estudos realizados em adultos ${ }^{(10-13)}$.

Utilizando-se o $\mathrm{pH}$ menor que 7, a especificidade foi elevada, mas a sensibilidade foi relativamente baixa. Elevando-se o ponto de corte até 7,2, manteve-se especificidade semelhante, com aumento na sensibilidade. Os valores preditivos positivos foram elevados em ambos os níveis de $\mathrm{pH}$; já o risco relativo foi superior no nível de 7,2 do $\mathrm{pH}$. Esses achados também foram observados quando se excluíram da análise os líquidos purulentos pois os mesmos já teriam indicação de drenagem -, ressaltando-se a importância da análise desse parâmetro, quando os líquidos são de aspecto límpido ou turvo, pois nos purulentos praticamente já se tem a decisão do procedimento.

Os achados relativos à dosagem da glicose mostraram sensibilidade elevada na predição de drenagem, embora tenha sido inferior ao que é descrito na literatura(17). Quanto à especificidade, esta mostrou-se superior à encontrada por Poe et al. ${ }^{(17)}$. O risco relativo foi elevado ao analisar o conjunto de pacientes e ao excluir aqueles com líquido purulento à toracocentese. Os valores preditivos positivos foram discretamente inferiores aos encontrados na análise do $\mathrm{pH}$. Esses resultados são compatíveis com o que tem sido descrito, pois as alterações de $\mathrm{pH}$ antecedem às da glicose em derrames pleurais complicados ${ }^{(18-}$ 21). Esse achado reveste-se de importância especial à medida que a análise do conteúdo de glicose é disponível na maioria dos centros, enquanto a análise do $\mathrm{pH}$ muitas vezes não é. Isso ocorre porque alguns laboratórios não permitem o uso dos aparelhos de gasometria para leitura do $\mathrm{pH}$ pelos riscos de dano ao aparelho e não dispõem de equipamentos específicos para análise isolada do $\mathrm{pH}$.

No presente estudo, encontraram-se niveis elevados de DHL no líquido pleural, mas valores elevados foram registrados tanto em pacientes que evoluíram com drenagem como nos tratados apenas com toracocentese e antibióticos. Seu valor preditivo positivo foi inferior ao dos outros parâmetros quando se analisaram os líquidos pleurais em geral e somente os não purulentos; os riscos relativos ti- 
veram valores inferiores aos dos obtidos com as outras análises. Tais resultados estão de acordo com os de outros autores e demonstram que a DHL, em valores superiores a 1.000UI/l, é um exame sensível, mas pouco específico, com limitação na sua aplicabilidade clínica ${ }^{(6,11)}$.

Deve-se considerar, também, que, dos pacientes drenados, 20 apresentavam líquido purulento e em 19 houve crescimento bacteriano no líquido pleural, situações consideradas como inequívocas para a realização de drenagem pela maioria dos autores ${ }^{(11,15)}$. Por outro lado, os achados bioquímicos foram semelhantes nos pacientes que apresentavam líquidos purulentos e não-purulentos quanto à decisão de drenagem. Esse fato sugere que as alterações estudadas $(\mathrm{pH}$, glicose e DHL) representam o que Light caracterizou como derrame pleural complicado num momento anterior à modificação macroscópica para líquido purulento e, portanto, ajudam na sua caracterização nesta fase $e^{(11)}$.

Destaca-se também que os cuidados metodológicos deste estudo permitiram avaliar o comportamento dos parâmetros bioquímicos no material coletado. Se o processamento do material não é imediato ou se não há adequada refrigeração, os valores tendem a alterar-se, prejudicando seu uso ${ }^{(21)}$.

Uma possivel limitação do uso de parâmetros bioquímicos na indicação de drenagem seria a não realização de exames comparativos de níveis séricos de glicose, $\mathrm{pH}$ e DHL. Estes exames não foram realizados pelo embasamento teórico em estudos que relatam que os achados bioquímicos encontrados no líquido pleural são, predominantemente, devidos a fenômenos locais da presença ou não de bactérias e suas conseqüências na composição do líquido pleural. Potts et al. compararam o $\mathrm{pH}$ e a glicose sistêmicos com os niveis pleurais: de 25 pacientes estudados, 11 apresentavam $\mathrm{pH}$ menor que 7,30, mas nenhum, acidose sistêmica ${ }^{(14)}$. Concentrações de glicose menores que $60 \mathrm{mg} / \mathrm{dl}$ foram observadas no líquido pleural de dez pacientes, sem que houvesse nenhum caso, entre estes, de hipoglicemia sistêmica. No estudo de Taryle et al., em apenas um dos 46 pacientes com pH pleural menor que 7,30 configurava-se acidose sistêmica; segundo o autor, o valor encontrado nesse caso $-6,61 \mathrm{de}$ $\mathrm{pH}$ pleural - era muito baixo para ser decorrente apenas de acidose sistêmica ${ }^{(18)}$.

\section{REFERÊNCIAS}

1. Ochsner A. History of thoracic surgery. Surg Clin North Am 1966; 46:1355-1376.

2. Somers J, Faber LP. Historical developments in the management of empyema. Surg Clin North Am 1996;6:403-418.

3. Peters RM. Empyema thoracis: historical perspective. Ann Thorac Surg 1989;48:306-308.

4. Light RW, MacGregor MI, Ball WC, Luchsinger PC. Diagnostic significance of pleural fluid $\mathrm{pH}$ and $\mathrm{pCO}_{2}$. Chest 1973;64:591-596.
Por não justificar-se a realização de gasometria arterial na maioria dos pacientes, não foi feita, neste estudo, a análise do $\mathrm{pH}$ sistêmico. Embora alguns autores sugiram que a leitura do $\mathrm{pH}$ sanguíneo deva ser realizada concomitantemente com a leitura do $\mathrm{pH}$ pleural, outros sugerem não adotar essa conduta, apoiando-se no fato de que a acidose pleural é um fenômeno localizado ${ }^{(18,19,21,22)}$. Também não se realizou a dosagem concomitante da glicose sistêmica, pois tem-se demonstrado que as alterações ocorridas devem-se a fatores inflamatórios, restritos ao espaço pleural ${ }^{(19-21)}$. Assim como também descrito por outros autores, não se observaram alterações nos valores da glicose pleural nos pacientes que recebiam infusão sistêmica de solução glicosada no momento da toracocentese $55 \%$ das crianças ${ }^{(20,21,23)}$. Limthongkul, em estudo experimental em adultos, administrou glicose intravenosa em altas concentrações e realizou medidas seriadas de glicose sérica e pleural simultaneamente, tendo observado que, apesar do aumento dos níveis séricos de glicose, não houve elevação das concentrações de glicose no líquido pleu$\mathrm{ral}^{(21)}$. Segundo Light et al., a dosagem de DHL pleural maior que 200UI/l, taxa de DHL líquido pleural/sérica maior que 0,6 , assim como a taxa de proteínas no líquido pleural/sérica maior que 0,5 , são parâmetros que podem ser utilizados para o diagnóstico diferencial entre exsudatos e transudatos e que a presença de apenas um já é suficiente para caracterizar um exsudato ${ }^{(9)}$. Em crianças predominam as efusões pleurais associadas a processos infecciosos pulmonares, que são, portanto, exsudatos. Por conseqüência, são desnecessários estudos para distinguir exsudatos de transudatos, a menos que a criança apresente uma doença de base que possa causar transudato.

Através do presente estudo, conclui-se que os critérios de Light et al. podem apoiar a decisão de drenagem torácica de derrame pleural parapneumônico em líquidos não purulentos em crianças. A disponibilidade de exames como a glicose e $\mathrm{pH}$ permite essa tomada de decisão com melhor predição que a DHL.

\section{AgradeCimentos}

Os autores agradecem ao Prof. Jarbas Oliveira pelo auxílio na realização das análises bioquímicas e ao Prof. Dr. José Antônio Flôres pela análise das radiografias.

5. Calnan WL, Winfield BJO, Crowley MF, Bloom A. Diagnostic value of the glucose content of serous pleural effusions. BMJ 1951;2:1239-1240.

6. Fernandes ALG, Nery LE, Nakatani J, Uehara C, Ratto OR. Avaliação do valor propedêutico da desidrogenase láctica nos derrames pleurais. Rev Assoc Med Bras 1979;25:91-93.

7. Pettersson T, Ojala K, Weber TH. Diagnostic significance of pleural fluid lactate concentrations. Infection 1985;13:257-259. 
8. Klockars M, Weber T, Tanner P, Hellström P, Pettersson T. Pleural fluid ferritin concentrations in human disease. J Clin Pathol 1985;38: 818-824

9. Light RW, MacGregor MI, Luchsinger PC, Ball WC. Pleural effusions: the diagnostic separation of transudates and exudates. Ann Intern Med 1972;77:507-513.

10. Light RW, Girard WM, Jenkinson SG, George RB. Parapneumonic effusions. Am J Med 1980;69:507-512.

11. Light RW. A new classification of parapneumonic effusions and empyema [editorials]. Chest 1995;108:299-301.

12. Heffner JE, Brown LK, Barbieri C, DeLeo JM. Pleural fluid chemical analysis in parapneumonic effusions - A meta-analysis. Am J Respir Crit Care Med 1995;151:1700-708.

13. Andrews NC, Parker EF, Shaw RR, Wilson NJ, Webb WR. Management of nontuberculous empyema - A statement of the subcommittee on surgery. Am Rev Respir Dis 1962;85:935-936.

14. Potts DE, Levin DC, Sahn SA. Pleural fluid $\mathrm{pH}$ in parapneumonic effusions. Chest 1976;70:328-331.

15. Hoff SJ, Neblett WW, Edwards KM, Heller RM, Pietsch JB, Holcomb Jr GW, et al. Parapneumonic empyema in children: decortication hastens recovery in patients with severe pleural infections. Pediatr Infect Dis J 1991;10:194-199.
16. Kiertsman B. Derrames pleurais parapneumônicos na infância: análise da evolução clínica e sua implicação terapêutica [dissertação]. São Paulo: Faculdade de Ciências Médicas da Santa Casa de São Paulo - Departamento de Pediatria, 1995.

17. Poe RH, Marin MG, Israel RH, Kallay MC. Utility of pleural fluid analysis in predicting tube thoracostomy/decortication in parapneumonic effusion. Chest 1991;100:963-967.

18. Taryle DA, Good JT, Sahn SA. Acid generation by pleural fluid: possible role in the determination of pleural fluid pH. J Lab Clin Med 1979; 93:1041-1046.

19. Sahn SA, Potts DE. Turpentine pleurisy in rabbits: a model of pleural fluid acidosis and low pleural fluid glucose. Am Rev Respir Dis 1978; 118:893-901.

20. Potts DE, Taryle DA, Sahn SA. The glucose-pH relationship in parapneumonic effusion. Arch Intern Med 1978;138:1378-1380.

21. Limthongkul S. Elucidation on acidity and low glucose concentration in parapneumonic effusion. J Med Assoc Thai 1991;74:224-228.

22. Good JT, Taryle DA, Maulitz RM, Kaplan RL, Sahn SA. The diagnostic value of pleural fluid $\mathrm{pH}$. Chest 1980;78:55-59.

23. Mocelin HT. Fatores preditivos para drenagem de derrames pleurais parapneumônicos em crianças [dissertação] Porto Alegre: Universidade Federal do Rio Grande do Sul, Departamento de Pediatria, 1997. 